\title{
Mycophenolate Mofetil (MMF) for the treatment of juvenile onset systemic lupus erythematosus
}

FF Falcini*1, CS Capannini ${ }^{1}$, MG Martini ${ }^{2}$, LTF La Torre ${ }^{3}$, VA Vitale ${ }^{3}$, NF Nacci ${ }^{1}$, MCM Matucci Cerinic ${ }^{1}$, CR Cimaz ${ }^{4}$ and ZF Zulian²

Address: ${ }^{1}$ Department of Biomedicine, Division of Rheumatology, Transition Unit, University of Florence, Florence, Italy, ${ }^{2}$ Department of Paediatrics, Rheumatology Unit, University of Padua, Padua, Italy, ${ }^{3}$ Department of Paediatrics, Rheumatology Unit, University of Messina, Messina, Italy and ${ }^{4} \mathrm{~A}$. Meyer Children's Hospital, Rheumatology Unit, University of Florence, Florence, Italy

* Corresponding author

from I5 ${ }^{\text {th }}$ Paediatric Rheumatology European Society (PreS) Congress

London, UK. 14-17 September 2008

Published: 15 September 2008

Pediatric Rheumatology 2008, 6(Suppl I):P234 doi:10.1 I86/I546-0096-6-SI-P234

This abstract is available from: http://www.ped-rheum.com/content/6/SI/P234

(C) 2008 Falcini et al; licensee BioMed Central Ltd.

\section{Aim}

To evaluate the efficacy and safety of MMF in jo-SLE in a multicenter study.

\section{Methods}

Medical charts of 26 pts, 25 F, 1 M, mean age at SLE diagnosis 12.7 yrs (range 5-18), mean age at MMF starting 15.9 yrs (range 7.5-26.8), followed in Florence, Padua, and Messina, Italy, treated with MMF from 2004 to 2007, were retrospectively analyzed. Clinical and laboratory evaluation included: blood count, ESR, CRP, ANA, antidsDNA, LFT, coagulation, C4, renal function, Coombs' test, aCL, antiß2GPI and LAC at baseline and every 6 months. Disease activity was monitored by the SLEDAI score. Treatment duration was $24 \pm 14.8$ months (range 2-52). MMF (1.5-2 g/day) was started due to steroid toxicity $(\mathrm{n}=9$ pts), CyA toxicity $(\mathrm{n}=5)$, disease activity $(\mathrm{n}=$ 8 ) or nephropathy progression despite previous immunosuppression $(\mathrm{n}=4) .9 / 26$ pts, before MMF had renal disease (7 WHO Class IIb, 1 Class III, 1 Class IV). In 5/9 MMF was the first treatment, while $4 / 9$ had received immunosuppressants.

\section{Results}

MMF was effective in reducing disease activity, steroid sparing in 14/26 (54\%), stabilizing the disease in $8(31 \%)$ and ineffective in $4(15 \%)$. In $9 / 13$ (69\%) without renal involvement a good response was registered. Among pts with renal involvement, MMF was effective in 5/13
(38\%), partially effective in 4 (31\%) and ineffective in 4 (31\%). 2 pts stopped MMF for diarrhoea and abdominal pain.

\section{Conclusion}

MMF seems to be effective and safe in jo-SLE, especially in patients without renal involvement. SLEDAI scores were significantly reduced at 6 and 12 months; $\mathrm{p}<0.05$. 